\title{
Wireless Charging of Battery in Electrical Vehicle using Solar Energy
}

\author{
Manoj D. Patil ${ }^{1}$ \\ ${ }^{1}$ Assistant Professor, \\ Department of Electrical Engineering, \\ Annasaheb Dange College of Engineering and Technology, \\ Ashta, District-Sangli, State-Maharashtra, \\ India. Pin Code-416301 \\ Rutuja V. Nerlekar ${ }^{2}$
${ }^{2}$ UG Student, \\ Department of Electrical Engineering, \\ Annasaheb Dange College of Engineering and Technology, \\ Ashta, District-Sangli, State-Maharashtra, \\ India. Pin Code-416301
}

\author{
Ankita S. Patil ${ }^{3}$ \\ ${ }^{3}$ UG Student, \\ Department of Electrical Engineering, Annasaheb Dange \\ College of Engineering and Technology, \\ Ashta, District-Sangli, State-Maharashtra, \\ India. Pin Code-416301 \\ Namrata M. Raut ${ }^{4}$ \\ ${ }^{4}$ UG Student, \\ Department of Electrical Engineering, Annasaheb Dange \\ College of Engineering and Technology, \\ Ashta, District-Sangli, State-Maharashtra, \\ India. Pin Code-416301
}

\author{
Ankita M. Virbhakt ${ }^{5}$ \\ ${ }^{5}$ UG Student, \\ Department of Electrical Engineering, \\ Annasaheb Dange College of Engineering and Technology, Ashta, \\ District-Sangli, State-Maharashtra, India. Pin Code-416301
}

\begin{abstract}
Energy is available in various forms from different natural sources such as solar energy, Nuclear energy and Chemical energy of fuels. The paper gives wireless charging techniques for electrical vehicle using solar energy. The fuel existing cars produces noise, air pollution and it produces major effects on an environment. But, the wireless charging technology overcome this pollution problems. Wireless Power Transmission [WPT] is very reliable, efficient, noiseless and pollution free technology.
\end{abstract}

Keyword: WPT-Wireless Power Transmission, EV-Electrical Vehicle, IPT-Inductive Power Transfer.

\section{INTRODUCTION}

Now a day, the world facing most serious problem is the energy demand [1]. Electrical energy is produced from energy available in various forms in nature i.e. from the sun, water, the wind and nuclear energy. Out of these sources, at present sun energy is primarily used for generation of electrical energy. In the last two to three years wireless power transmission [WPT] is one of the fastest growing technologies for power transmission without using cables. This newly advanced technology is very reliable, and efficient. In present days, the wireless power transmission is become very necessary because to continue the driving electrical car thus it become profitable.

In the last two decades power transmission using inductive and magnetic coupling we see. This paper is about to charge the battery by using solar energy and it can support more than one devices. Thus it become more beneficial. Power transmission using cables lost $25-30 \%$ power and by using cables for power transmission it has many accidents But
WPT is completely safe for human. Thus, it is become safe for environment and for climate than conventional cars. Modern wireless power transmission techniques are more reliable, efficient. Wireless Power Transmission has improved significantly in the past $2-5$ years. The advantages of the Wireless Charging systems are given as below-1) Variable frequency Possible 2) It can support more than one device.

\section{LITERATURE REVIEW}

Nikola Tesla was the first who invented Wireless Power Transmission [WPT] technology in 1890 .He wanted to create the supply system without use of the wire thus he invented inductive and capacitive coupling system for WPT. he invented coil known as Tesla Coil.

Erhuvwu Ayisire has given the idea related charging system for Electrical vehicle [EV] [2]. N. Uthaya Banu, U. Arunkumar, A. Gokulakannan, M. K. Hari Prasad and A. B. Shathish Sharma has given the knowledge about the battery charging by using solar energy and it also analysed primary and secondary side in detail [1].The most difficult and important part while designing wireless charging system that is designing part of the coil. This paper gives knowledge about the Wireless Charging in Electrical Vehicle by using Solar Energy.

\section{NECESSITY}

Wireless power transmission has attracted the lots of the researches due to the several advantages. Now days the Global Warming become the most dangerous problems in now a day [1]. Wired charging has the many drawbacks. To 
resolve the issues of the wired charging system. Thus, now days wireless power transmission technology become more useful .Now days this techniques becomes need of the human life.

\section{BLOCK DIAGRAM}

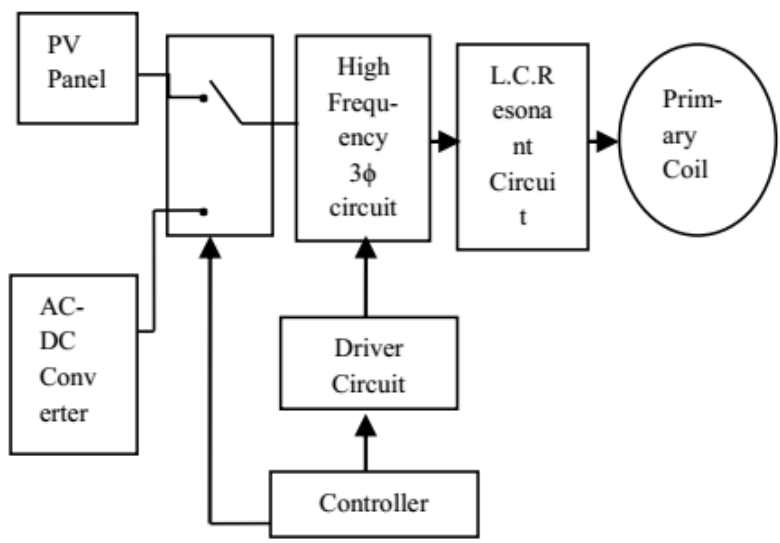

Fig.1: Primary Side

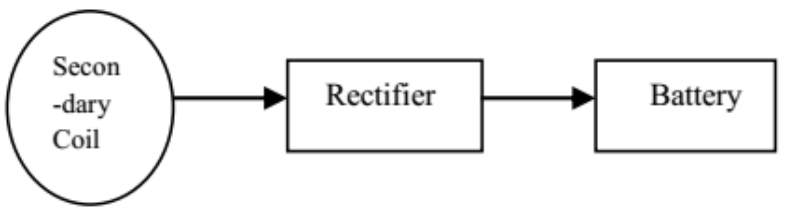

Fig.2: Secondary Side

In our project we use port which is act as a brain of the system. By varying port frequency will changed. We use $12 \mathrm{~V}$, $5 \mathrm{~A}$ transformer and for conversion of $\mathrm{AC}$ to $\mathrm{DC}$ we use rectifier on the secondary side of the system. In our project we design bridge rectifier which consists of four diodes (6A4) and one capacitor .Input for rectifier is coming from transformer which is step down the voltage from $230 \mathrm{~V}$ to $12 \mathrm{~V}$.The purpose behind use of the port is to convert the analog signal into the digital signal and for generation of the variable frequency. In this project we use MOSFET which can be ON at $50 \%$ of the duty cycle. Port gives the first signal to the Arudino. After getting signal from the port arudino gives the pulse to the optocoupler and then this pulse gives to the output side of the MOSFET. Output circuit of the MOSFET consists of the L.C. circuit.

As per shown in the Fig:1 Solar panel is placed on the top sides which are $(12 \mathrm{~V}, 20 \mathrm{~W})$.It uses the solar energy through photovoltaic effect. PV panel and AC to DC Converter both are connected to the high frequency inverter through the auto change over unit. Normally in the cloudy season supply from the sun is not available thus we can use MSEB supply. But sometimes this both supply system are available then we can store the supply which is get from the solar energy. In fig:2 we shows the secondary side of the system, In this secondary side we connect the secondary coil to the rectifier. A rectifier is connected to convert ac to dc which charges the battery of electric vehicle. On the secondary side we used special diode which is IN4148 the purpose of the use of this diode is it having fast switching charterstics.

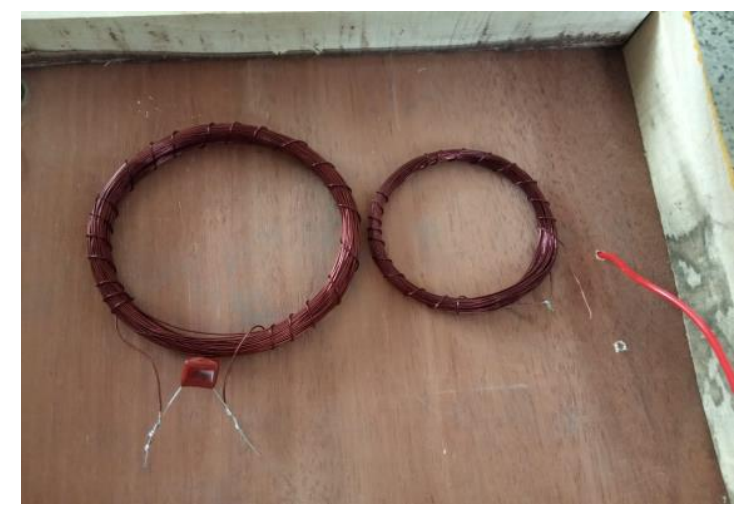

Fig.3: Set up for the primary and secondary coil

For wireless power transmission if we put large distance between the primary and secondary then this will affect on the variable frequency and whenever the frequency get changed then induced voltage on the secondary side get decreased. Thus for WPT techniques we can't put more distance between two coils and if we want to put more distance between primary and secondary coils then required specification for all components must have high ratings with high variable frequency respectively.

Basic concepts related to WPT in EV -WPT means transmission of energy from one place to another without use of wires. WPT technique is based on the electromagnetic induction principle; emf is induced in the secondary coil.

Table 1: Different types of the WPT techniques

\begin{tabular}{|c|c|}
\hline \multicolumn{2}{|c|}{ Wireless Power Transmission Technology } \\
\hline Near Field or Non Radiative & Far-Field or Radiative \\
\hline
\end{tabular}

Near Field or Non Radiative-Near field technology is useful for short distance by using inductive coupling between two coils. It is useful for charging devices likephone, electrical brushes, inductive cooking.

Far-Field or Radiative-For long distance transmission far field techniques is useful. By using electromagnetic radiation or Laser beams wireless power transmission technique can be applicable. This radiative far field technique is applicable for solar power satellites.

Table 2: Shows the different distance between two coils and induced voltage in secondary coil.

\begin{tabular}{|c|c|}
\hline $\begin{array}{c}\text { Distance } \\
(\mathrm{mm})\end{array}$ & $\begin{array}{c}\text { Voltage } \\
(\mathrm{V})\end{array}$ \\
\hline 5 & 4.99 \\
\hline 10 & 4.62 \\
\hline 15 & 4.44 \\
\hline 20 & 3.33 \\
\hline 25 & 2.77 \\
\hline 30 & 1.65 \\
\hline
\end{tabular}

As per the above table shown the reading of output voltage vs distance between primary and secondary coil as you increases the distance between two coils then induced voltage in the secondary coil will be decreases. Thus in proposed project we use port to vary frequency and using variable frequency we 
get the required induced voltage in the presences of the 3 to $5 \mathrm{~mm}$ distance between the coils respectively.

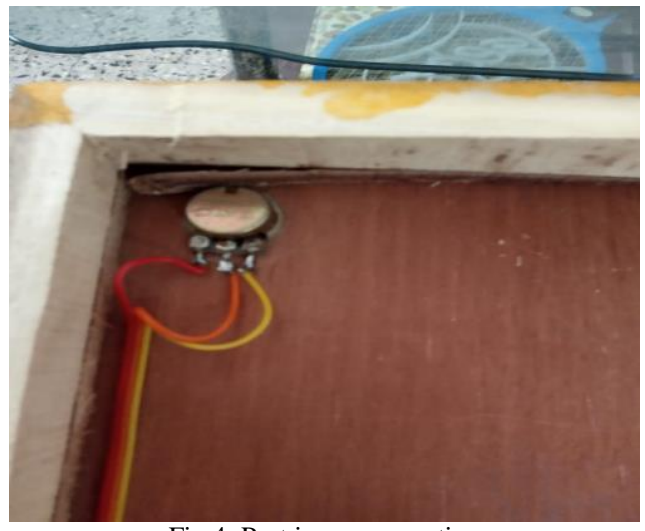

Fig.4: Port inner connection

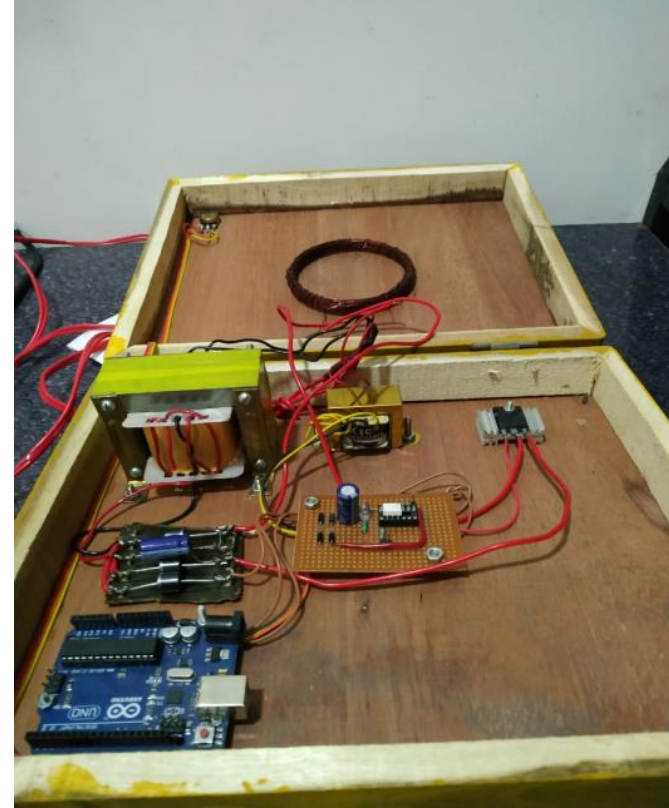

Fig.5: Hardware kit

\section{CONCLUSION}

It is seen that the distance between primary coil and secondary coil is decreases. When it comes to voltage generated on secondary side as the distance between two coils increases the induced voltage decreases. Hence for wireless charging, the trade off is maintaining the distance between primary and secondary coil for smooth voltage characteristics. A voltage regulator is useful at receiver side for obtaining fixed voltage.

\section{FUTURE SCOPE}

A. Smart Charging Station- Smart EV charging is worked on the basis of the back-end solution. if the charging stations are connected to the cloud ,then they can managed based on the different signals such as local energy consumption. By using smart charging stations we can easily find available charging points also we get fast charging, charge safer, save money and the environment and also avoid arguments with neighbors.
B. Renewable energy based charging stationRenewable energy based charging stations consists of the both solar and wind energy. Charging stations based on the solar or wind energy it is useful to prevent the environment from the pollution. By using solar energy based charging station we can produced power during the day and it can be used at night to charge EVs.

\section{REFERENCES}

[1] N. Uthaya Banu, U. Arunkumar, A. Gokulakannan, M. K. Hari Prasad and A. B. Shathish Sharma "Wireless Power Transfer in Electric Vehicle by Using Solar Energy" Asian Journal of Electrical Sciences ISSN:2249-6297,Vol.7,No.1,2018,pp.6-9

[2] Erhuvwu Ayisire "Magnetic Resonance Coupling Modelling For Electric Vehicles Wireless Charging”. IEEE 2018

[3] Shubhangi Das, Kajal Pal, Prema Goswami, M. A. Kerawalla "Wireless power transfer in electric vehicles". International Journal of Applied Environmental Sciences, ISSN 0973-6077 Vol 13, Number 7(2018), pp.643-659

[4] Rajbansi Devmani Kamalbahadur, S Prabhu Ram, Kohar S. Suresh, M.R. Venugopitan, R. Karthikayan "Wireless Charging of Electric Vehicles by Solar Power Charging Station”. International Journal of ChemTech Research, CODEN (USA): IJCRGG ISSN: 0974 4290,Vol.10.No.14,pp 198-206,2017

[5] Miss Shital R. Khutwad. "Wireless Charging Systems For Electrical Vehicle" International Conference on Signal Processing, Communication, Power and Embedded System-2016

[6] Do Larn Mung, Kyaw Soe Lwin, Hla Myo Tun "Design And Construction Of Wireless Charging System Using Inductive Coupling" International Journal of Scientific \&Technology Research Volume 4,ISSUE 06,June 2015,ISSN 2277-8616

[7] Abhishek Gupta, Ankush Tandon, Akhilesh Jeriya, Naveen Tanwar, Ramesh Kumar, Dinesh Kumar "Automatic Wireless Mobile Charger' International Journal of Electrical and Electronics Research ISSN 2348-6988 Vol. 4,Issue 1,pp:(113-119),Month: January-March 2016.

[8] S. Y. Suryawanshi and M. D. Patil, "Implementation of a DC Side Sensor-less Cascaded H-Bridge Multilevel Converter for Photovoltaic System," 2019 3rd International Conference on Trends in Electronics and Informatics (ICOEI), Tirunelveli, India, 2019, pp. 1104-1108.

[9] M. D. Patil and R. G. Ramteke, "L-C filter design implementation and comparative study with various PWM techniques for DCMLI," 2015 International Conference on Energy Systems and Applications, Pune, 2015, pp. 347-352

[10] Manoj D. Patil, K. Vadirajacharya, Swapnil Khubalkar, "Design of fractional order controllers using constrained optimization and reference tracking method" in International Journal of Power Electronics and Drive Systems (IJPEDS), Volume-11, Issue-01, March 2020, pp. 291-301

[11] Manoj D. Patil, K. Vadirajacharya, "ALO optimized Neural Network Controlled Three Phase Five Level Cascaded H-Bridge Inverter for Integrating PV Panel with Smart Grid" in Institute of Advanced Scientific Research Publications; Journal of Advanced Research in Dynamical and Control Systems (JARDCS), Volume-10, Special Issue09, 2018, pp.2127-2139

[12] Manoj D. Patil, Rajendra B. Madake, Sonali L. Sawant, "Modeling and Simulation of Indirect Back EMF Detection Based Sensor Less Operation of PMBLDC Motor Drive" in Blue Eyes Intelligence Engineering \& Sciences Publications; International Journal of Engineering and Advanced Technology (IJEAT), ISSN: 2249-8958, Volume-9, Issue-1, pp.3857-3862, October 2019

[13] Manoj D. Patil, K. Vadirajacharya, "Performance Improvement of Renewable Energy Sources Inverter for Interface with Smart Grid” in International Journal of Research and Analytical Reviews (IJRAR), EISSN: 2348-1269, P-ISSN: 2349-5138, Volume-6, Issue-1, pp.157-163, January 2019

[14] Dhanshri B. Bhadke, Manoj D. Patil, "Operation and Control of a DC Micro-grid with Wind Power Generation and Energy Storage” in Blue Eyes Intelligence Engineering \& Sciences Publications; International Journal of Recent Technology and Engineering (IJRTE), ISSN: 2277 3878, Volume-8, Issue-2, pp.3972-3978, July 2019

[15] Manoj D. Patil, Mithun Aush, K. Vadirajacharya, "Grid Tied Solar Inverter at Distribution Level with Power Quality Improvement" in 
Research India Publications; International Journal of Applied Engineering Research, Print ISSN: 0973-4562, Online ISSN: 10871090, April 2015, Special Issues, Volume-10, Number-9, pp.8741-8745

[16] Manoj D. Patil, "Power Quality Improvement for Energy Saving" in Novateur Publications; International Journal of Innovations in Engineering Research and Technology, ISSN: 2394-3696, Volume-3, Issue-5, May-2016, pp.89-94

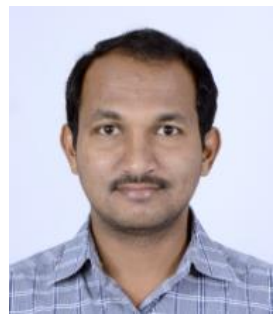

Manoj D. Patil was born in Sangli, Maharashtra, India, in 1987. He has received his B.E. Degree in Electrical Engineering from Shivaji University Kolhapur, Maharashtra, India in 2009, and the M.E. Degree in Electrical Power Systems from Government College of Engineering Aurangabad (which is affiliated to Dr. Babasaheb Ambedkar Marathwada University Aurangabad), Maharashtra, India in 2011. He is working as Assistant Professor at Annasaheb Dange College of Engineering \& Technology, Ashta, Sangli, Maharashtra since July 2011.He is currently working toward the Ph.D. degree with the Division of Electrical Engineering at Dr. Babasaheb Ambedkar Technological University, Lonere, Raigad, Maharashtra, India.

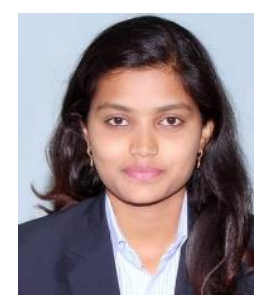

Rutuja Vijay Nerlekar was born in Islampur, Maharashtra, India, in 1998. Currently pursuing B.E.in Electrical Engineering at Annasaheb Dange College of Engineering\& Technology, Ashta

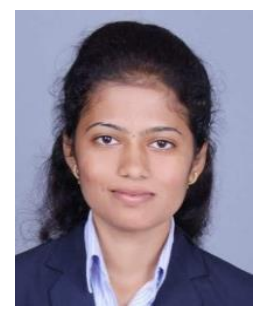

Ankita Sambhaji Patil was born in Islampur, Maharashtra, India, in 1998. Currently pursuing B.E. in Electrical Engineering at Annasaheb Dange College of Engineering \& Technology, Ashta

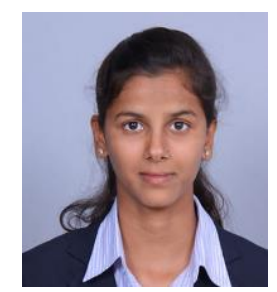

Namrata Mahadev Raut was born in Sangli, Maharashtra, India, in 1998. Currently pursuing B.E.in Electrical Engineering at Annasaheb Dange College of Engineering \& Technology, Ashta

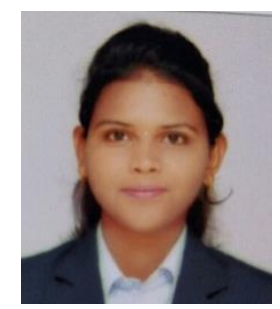

Ankita Mukund Virbhakt was born in Ashta, Maharashtra, India, in 1998. Currently pursuing B.E. in Electrical Engineering at Annasaheb Dange College of Engineering \& Technology, Ashta 